\title{
Quick recognition of a threatened airway in a patient with a swelling in the neck
}

\author{
Annemieke M Peters van Ton, Jose Volders, David H Tjan
}

Department of Intensive Care, Gelderse Vallei Hospital, Ede, The Netherlands

\section{Correspondence to}

David H Tjan,

tjand@zgv.nl

Accepted 9 September 2014

\section{DESCRIPTION}

An 80-year-old Caucasian man visited the ear, nose and throat outpatients' clinic with a progressive swelling in the neck, acute dyspnoea and a mild inspiratory stridor. Furthermore, he experienced progressive swallowing disorders. Since 1995 he has been known with an asymptomatic

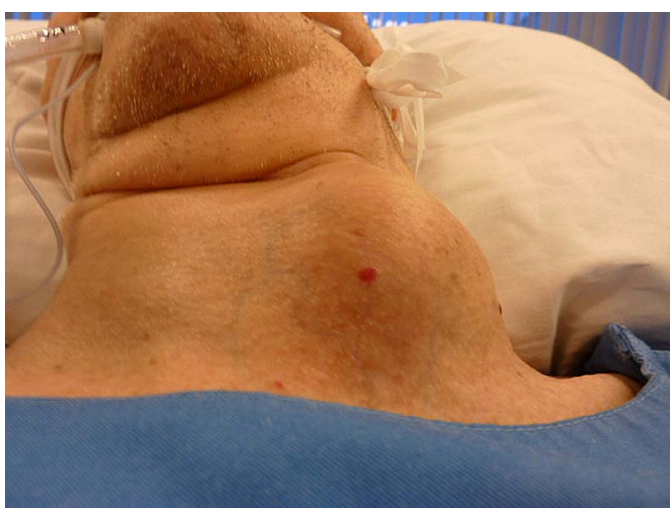

Figure 1 A picture of an 80-year-old intubated patient with an asymmetrical multinodular goiter, which compresses the trachea, leading to dyspnoea and an inspiratory stridor. benign goitre for which he did not receive treatment. The patient was admitted to the hospital and during admission he developed progressive dyspnoea with desaturations and an increase of the inspiratory stridor. Physical examination revealed a very large swelling in the lower part of the neck (figure 1), fluctuating during palpation. The patient underwent endotracheal intubation for

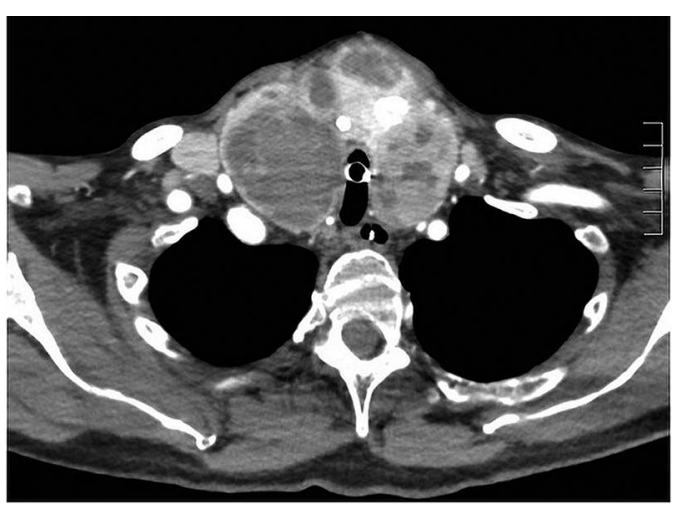

Figure 2 CT scan of the neck and thorax of an 80 -year-old intubated patient with a large multinodular goiter and tracheal compression.
To cite: Peters van Ton AM, Volders J, Tjan DH. BMJ Case Rep Published online: [please include Day Month Year] doi:10.1136/bcr-2014207166

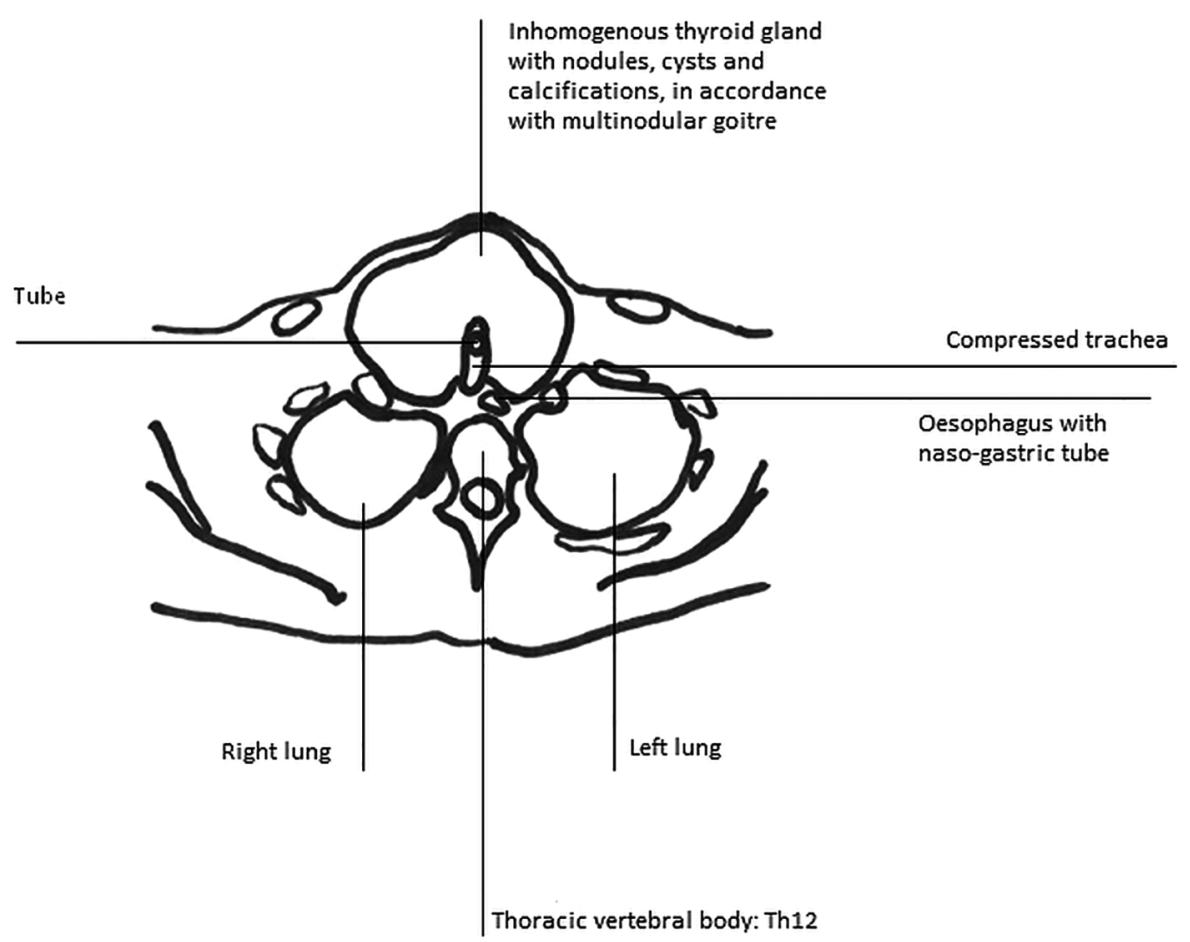

Figure 3 Anatomical structures in a CT scan of the neck and thorax of an intubated patient with a large multinodular goiter and tracheal compression. 
airway protection. Fiberoptic equipment was prepared prior to that however a normal intubation was possible without complications.

Laboratory studies revealed subclinical hyperthyroidism. CT scan of the neck showed a multinodular goitre with tracheal compression (figures 2 and 3). The patient was transferred to a head-neck centre where they performed a total thyroidectomy. The patient could be extubated 1 day after surgery. Pathology studies revealed a nodular hyperplasia, consistent with multinodular goitre.

Despite sufficient iodine uptake through nutrition in Western countries, goitre remains a common condition. ${ }^{1}$ Symptoms develop through compression of vital structures in the neck or upper thoracic cavity. A large goitre can even lead to tracheal compression. $^{2}$ This image shows an impressively large goitre that is not seen regularly in Western countries, but should be recognised as a potentially dangerous condition. When the first signs of a threatened airway present, admission to an intensive or medium care unit is necessary to monitor these patients closely.

\section{Learning points}

- Goitre may occasionally cause tracheal compression.

- Dyspnoea and an inspiratory stridor are the first signs of a threatened airway.

- Every patient with an inspiratory stridor should be closely monitored on an intensive or medium care unit.

Competing interests None.

Patient consent Obtained.

Provenance and peer review Not commissioned; externally peer reviewed.

\section{REFERENCES}

1 Tonacchera M, Pinchera A, Vitti P. Assessment of nodular goitre. Best Pract Res Clin Endocrinol Metab 2010;24:51-61.

2 Jauregui $R$, Lilker ES, Bayley A. Upper airway obstruction in euthyroid goiter. JAMA 1977;238:2163-6.

Copyright 2014 BMJ Publishing Group. All rights reserved. For permission to reuse any of this content visit http://group.bmj.com/group/rights-licensing/permissions.

BMJ Case Report Fellows may re-use this article for personal use and teaching without any further permission.

Become a Fellow of BMJ Case Reports today and you can:

- Submit as many cases as you like

- Enjoy fast sympathetic peer review and rapid publication of accepted articles

- Access all the published articles

- Re-use any of the published material for personal use and teaching without further permission

For information on Institutional Fellowships contact consortiasales@bmjgroup.com

Visit casereports.bmj.com for more articles like this and to become a Fellow 